\title{
Institutional Morality and the Principle of National Self-Determination
}

[The paper is a part of a larger project of critically examining the value and limits of the principle of national self-determination. Many objections have been raised to this principle, but I cannot consider all of them here. In this paper, I will consider only the problems raised by Allen Buchanan's challenge of institutional morality.]

\section{Introduction}

The principle of national self-determination holds that a national community, simply by virtue of being a national community, has a prima facie right to decide whether it should create its own sovereign state (Margalit and Raz 1990; Miller 1995; Nielsen 1998; Tamir 1993). ${ }^{1}$ In the literature, any theory that endorses this principle or affirms the said right is referred to as the national self-determination theory (hereafter the NSD theory). It is a theory of secession, because it specifies the conditions a group must fulfill to be morally justified in seceding from the current sovereign regime and creating its own state (Buchanan 1997; Norman 1998).

Since the publication of his book Secession, Allen Buchanan has developed a methodological framework with which he evaluates different theories of secession, including the NSD theory (1991). ${ }^{2}$ An important claim Buchanan makes is that because the right to secede is

\footnotetext{
${ }^{1}$ This principle is different from Margaret Moore's, which holds that state boundaries should be drawn in a way that approximates the boundaries of national communities (2001). It is also different from another principle that holds that each national group has a right to create its own sub-state, autonomous government (Kymlicka 1995; Patten 2002).

2 The arguments from Buchanan considered here are from his 1997 article "Theories of Secession" and his 2004 book Justice, Legitimacy, and Self-Determination. Notice that there is an evident tone switch. In the earlier article, he prioritizes the institutional aspect because he thinks that in practice, it is the more urgent question. However, in his recent book he suggests that we must study the right to secede's institutional dimension because this right is
} 
inherently institutional, any adequate theory of secession must include, as an integral part, an analysis of institutional morality. Those failing to do so can hardly be satisfactory. Because the NSD theory blatantly lacks such an analysis, Buchanan concludes that this theory is inherently flawed.

In this paper, I will consider Buchanan's theory of institutional morality and related critiques of the NSD theory. The discussion is divided into three parts. In section 2, I give an overview of the important concepts in Buchanan's framework, including the basic idea of institutional morality, the related specific criteria, and the resulting critiques of the NSD theory. In section 3, I respond to the challenges raised by Buchanan's specific criteria and explain why these criteria actually fail to reflect the real demands of institutional morality. In section 4, I consider the responses from NSD theorists to the challenge of institutional morality. I show that Buchanan and the NSD theorists both make the wrong assumption that the difference between them lies in the way they engage in political theorizing - the NSD theorists began by ideal theorizing, while Buchanan by nonideal theorizing. This view of their debate is misconceived. I explain an alternative understanding of the concept of institutional morality, which will improve the way we compare different theories of secession. Here, the aim is not to pronounce a winner in this debate, but to clarify some confusion shared by both sides.

\section{An Overview of Buchanan's Framework}

Let us begin by considering the methodological framework with which Buchanan evaluates different theories of secession. It involves three important claims. First, the right to secede is inherently institutional; accordingly, any adequate theory must examine how the inclusion of this 
right would affect existing institutions. Second, to determine a right's impact on current institutions, we must engage in holistic institutional moral reasoning. This involves first identifying the morally defensible elements of these institutions, and then considering in a holistic manner whether the recognition of a new right would be compatible with them. Third, to help us determine whether a theory of secession is acceptable, Buchanan proposes five specific criteria to test whether it meets the methodological requirements of institutional morality. Next, I will explain these ideas in detail.

\subsection{The Right to Secede is Inherently Institutional}

In order to get a clear picture of Buchanan's framework, we must begin by considering his claim that the right to secede is inherently institutional. Buchanan suggests that whenever a group claims to have the right to create its own state, this claim implies two things: first, the group is morally justified in attempting to create its own legitimate state; second, others are morally prohibited from interfering with their so doing. He points out that both claims are claims about institutions - they both invoke the concept of a legitimate state, which is quintessentially an institutionally defined entity. Buchanan argues that "to be a legitimate state is to be an institutionally defined entity, an entity that has a certain status according to the institutions of international law (2004: 15)." Thus, to assert a right to secede is to make a claim concerning relevant institutions. Consequently, any assertion of a right to secede is inherently institutional (2004: 14-8; 345-8).

What does this mean for the recognition of a nation's right to create its own state? How does it affect different theories of secession? Buchanan suggests that because such a right is unavoidably institutional, its incorporation would inevitably have some impact-positive, 
negative, or both — on existing institutions. Thus, to determine whether relevant institutions should recognize the right to secession, we must look at the right's impacts on these institutions and see how well it fits with them. If the inclusion of a new right would lead to institutional improvement, then we should include it. On the other hand, if its inclusion would lead to the deterioration or regression of these institutions, then we should not include it. How, then, can we know whether the recognition of the new right would lead to progress or regress? How should we decide whether a new right should be institutionally recognized?

\subsection{Holistic Institutional Morality}

In order to determine whether the formal recognition of a right would lead to progress or regress, Buchanan suggests that philosophers must engage in what he calls institutional moral reasoning (2004:345). It is rather difficult to grasp the content of this idea, partly because it is composed of a complicated list of values and principles that govern different institutions. It is also difficult because Buchanan never explicitly explains or defines this idea. When employing this idea to criticize other theories, he seems to think that its meaning is self-evident. As we shall see shortly, this lack of clarity results in serious confusion in the debate between Buchanan and his opponents. Nevertheless, I find in his discussion several clues we can work with to better understand this idea. Here, I will try to construct what I take to be the best interpretation of the idea of institutional morality.

First, we must begin by identifying factors and elements of existing institutions that would be affected by the inclusion of a new right; that is, we must look at what would be affected. Buchanan suggests that we start by looking for what he calls the morally defensible elements of existing institutions, namely, the moral principles and values that guide our actual practice (1997: 
32). Existing institutions are created to preserve certain important moral principles and values; accordingly, these principles and values can serve as guidelines to help us determine a right's impact on current institutions. Thus, to see how a right would affect existing institutions, we must first identify the moral principles and values that guide them.

Second, after identifying the principles and values that would be affected, we must estimate how and the extent to which they would be affected. The inclusion of a new right would inevitably affect existing institutions in a variety of ways. To use a highly simplified example, two important moral values in existing political institutions are stability and equality. The institutional recognition of a new right may lead to the disruption of stability, but greatly enhance equality; or it may enhance stability slightly, but undermine equality greatly, etc. To determine which theory of secession is most plausible, we must estimate how the rights they propose to include affect those moral principles and values individually. This step would allow us to see which moral values would be harmed and which preserved. That is, it would allow us to preview what would be gained and what would be lost if a right were recognized. Without this step, we could neither estimate a right's impact nor determine if its inclusion would lead to progress.

Third, after identifying the moral principles and values of existing institutions and evaluating a new right's possible impact on them, the next step is to compare the estimated results. Notice that when we consider a right's impact, what we consider is not merely its impact on some particular principle or value; rather, we should consider its overall impact on the principles and values of existing institutions. Buchanan calls this holism (2004: 28, 345). It requires that we consider whether a right's formal inclusion would be compatible with "what is being assumed about the other principles that it will coexist with, how they fit together, and what the effects of their joint implementation [italics added] is likely to be (2004: 17)." The 
implementation of a right will affect not just some particular principle or value; it will often have a far-reaching impact on a wide variety of principles and values. Accordingly, we must consider its impact on all of them.

To be clear, this is not to say that we value all of these moral principles and values equally. Some principles are certainly more important than others, and we should assign them different weights accordingly. In addition, estimating a right's impact is hardly a precise science. Much will depend on the most reasonable conjecture or even speculation on the matter. Nonetheless, in order to determine whether the recognition of a new right would lead to progress or regress, we must try our best to measure a right's general impact on the principles and values of existing institutions.

Lastly, some of the important factors that should be taken into consideration while engaging in institutional moral reasoning include a right's feasibility as well as its likely consequences. To determine whether a right is feasible, one must take into consideration whether that right could be "embodied in institutions (2004: 12)." Some very important interests or moral rights cannot be feasibly protected by institutional recognition; for instance, the right to have friends. Moreover, we must also consider the likely consequences of incorporating such a rightwhether its inclusion would lead to serious human rights violations or other highly undesirable consequences (2004: 14). In other words, we need to evaluate the possible costs of a right's implementation.

These features of institutional morality are still very abstract and have yet to give us any specific guidance on how to assign values to or estimate the impact of different principles and values. For the time being, it suffices for the readers to see that Buchanan's methodology puts great emphasis on a right's overall, holistic impact on institutions. I will revisit this idea in 
section 4 when I consider the opponent's critique of Buchanan's methodology.

\subsection{Specific Criteria}

Although many theories blatantly lack an analysis of institutional morality, this does not automatically mean that they must be incompatible with the demands of institutional morality. Consider the following analogy. Some drivers never took a driver's license test; in spite of this, they could be good drivers. Likewise, although most theories of secession never investigate the demands of institutional morality nor examine its compatibility with those demands, this does not mean that they must be incompatible. Because the content of institutional morality is yet to be determined, it is still possible that a theory which fails to consider its compatibility with institutional morality could actually be compatible with its demands.

In view of the lack of clear guidance regarding the demands of institutional morality, Buchanan proposes five specific criteria to help us examine which theories are compatible with these demands and which are not. The function of these criteria is to make explicit some of the most important requirements of institutional morality. He acknowledges that these criteria are not comprehensive and do not completely reflect the requirements of institutional morality. Nonetheless, they are enough to expose theories that are incompatible with these requirements. Their main function is to highlight theories that are seriously flawed when considered as "elements of an institutional morality articulated in a system of international law (1997: 41)."

Here I cannot consider in detail Buchanan's criteria. Very briefly, they are: (1) a cogent theory of territorial claim; (2) Progressive conservatism;" (3) Moral accessibility; (4) Incentive compatibility; and (5) Moral convergence (1997: 42-44; 2004: 348-350). ${ }^{3}$ I should also mention

\footnotetext{
${ }^{3}$ I should clarify that these five criteria come from Buchanan's book Justice, Legitimacy, and Self-determination. They are, presumably, developed and revised from the four criteria from his earlier article, "Theories of
} 
that, there is one criterion that I am not sure whether Buchanan still subscribes to because he does not mention it in his later work, Minimal Realism. This criterion requires that a theory be both morally progressive and minimally realistic. The former idea seems to be preserved in the idea of progressive conservatism; however, the criterion of minimal realism is not reflected by any of the five criteria just mentioned. This criterion requires that a principle have "a significant prospect of eventually being adopted in the foreseeable future, through the process by which international law is actually made (1997: 42)." I will say more about this criterion in 3.1.

\subsection{Buchanan's Critique of the National Self-Determination Theory}

Now that we have some rough idea of Buchanan's methodological framework, I will briefly explain his objections to the NSD theory. ${ }^{4}$ The details of these objections will be discussed in the following sections. The gist of Buchanan's objection is that first, the NSD theory fails to take seriously the institutional dimension of the right to secede; as one would then expect, it naturally also fails to engage in (holistic) institutional moral reasoning. Moreover, it fails to meet several of Buchanan's specific criteria. Let me begin by considering how these criteria affect the NSD theory.

\section{A Brief Examination of Buchanan's Criteria}

Although Buchanan acknowledges that the NSD theory may be widely supported and thus fulfill the requirement of moral convergence, he argues that it fails to fulfill other criteria

Secession"-_minimal realism, consistency with well-entrenched, morally progressive principles of international law, absence of perverse incentives, and moral accessibility. Although he names those criteria differently, Buchanan's earlier criteria include the last two of his newer version-incentive compatibility and moral convergence. The criterion that a theory be consistent with well-entrenched, morally progressive principles of international law is reflected in his methodological requirement that a theory engage in holistic institutional moral reasoning.

${ }^{4}$ Notice that Buchanan's criticism of the national self-determination theory is rather extensive. Not only does he use the above framework to criticize this theory, he also raises other objections to it - the Infeasibility Objection and the Equal Respect Objection (1996). 
(1997: 55). In particular, he believes that it fails to meet the requirements of minimal realism, incentive compatibility, and a good theory of territorial claim. Here, I cannot give a detailed response to Buchanan's challenge. Nonetheless, I will explain briefly why his criteria fail to show that the NSD theory is inadequate.

First, Buchanan argues that the NSD theory fails to meet the criteron of minimal realism. The reason is that the kind of policy the NSD theory prescribes would likely lead to the dissolution of actual states; being the actual law-makers of international law, these states are not likely to endorse such a policy. ${ }^{5}$ Therefore, the theory does not have a reasonable prospect of being accepted. Accordingly, it fails to satisfy the criterion of minimal realism.

Many supporters of the NSD theory acknowledge that their theory may not be accepted by actual states and would likely fail the criteria of minimal realism. However, they are not convinced that this provides a good reason to reject their argument. Kai Nielsen suggests that this requirement is based on realpolitik considerations, not moral ones (1998: 129). Margaret Moore argues that the requirement of minimal realism is unfair because many important civil rights once failed to meet this requirement (2001: 205). For instance, there was a time when the rights of slaves and women did not have a reasonable prospect of being accepted by actual lawmakers. However, this does not mean that these rights should be rejected. The fact that a right does not have a good chance of being recognized by actual lawmakers does not mean that it should not be accepted. Accordingly, even if the NSD theory is not likely to be incorporated by international law very soon, this does not matter. It should eventually be incorporated.

In addition, Buchanan argues that the formal recognition of a nation's right to secede

\footnotetext{
${ }^{5}$ One might suspect that actual states would not sanction policies that would contribute to their own disintegration merely because the power-holders would like to hold on to their power. True as that may be, Buchanan suggests that it is also because a legitimate state is the guardian of both its current and future generations of citizens, and thus has to the right to territorial integrity (1997: 46-49).
} 
could possibly create perverse incentives on the part of state governments to suppress national groups. In order to ensure its continued existence and prevent its own dissolution, a state government may wish to eliminate institutional arrangements that help preserve a nation's culture and its group identity (1997: 52-55). That way, it nips in the bud the formation of national identity and protects its own survival. Accordingly, the NSD theory would actually create incentives to institutionally suppress a group's identity; it therefore fails to meet the requirement of incentive compatibility.

I agree with Buchanan that in the process of law making, legislators should take into consideration whether the inclusion of a new rule or policy would create perverse incentives. However, we should be careful about the significance of these incentives and how we should respond to them. Here, the solution Buchanan prescribes is inadequate. Even if a state government had an incentive to eliminate the rights of national communities, it would not be morally justified in doing so. National communities have rights to institutional arrangements that protect their cultures. States do not have the right to eliminate these institutions. Instead of relinquishing a good institutional arrangement that could possibly lead to undesirable motives, we should try to design it in a way that would discourage this type of motive. Moreover, what does it mean that a policy can "create perverse incentives?" There is no necessary connection between the NSD theory and the incentives that Buchanan is concerned with. Different agents may respond differently to institutional changes. Some suggest that gay-rights activism creates perverse incentives, because by advocating gay-rights, the activists put pressure on conservatives to create laws that deny their rights. These activists may be imprudent, unwise, or even thoughtless, but should we therefore ask them to discontinue their activism? Factors about people's responses and motives should be considered by governmental officials who are 
concerned with how to effectively propagate a law. However, these factors would not undermine the (moral) soundness of a right. It is unfair to accuse theories of creating perverse incentivesthese incentives are the products not of these theories, but of the persons who react to them. Thus, Buchanan is wrong to suggest that the NSD theory should be rejected because it creates perverse incentives.

Lastly, Buchanan argues that the NSD theory contradicts the most cogent theory of territorial claim, namely his Just-Cause Theory (1999). According to this theory, a state that adequately performs the function of protecting human rights, democracy, and justice is entitled to the right of territorial integrity. Buchanan argues that every claim of a right to secede involves a claim to a piece of territory that belongs to some existing state. Thus, to claim the right to secede, the seceding group must prove that it has a legitimate claim to this territorial area and that its claim overrides that of the state (Brilmayer 1989). Such a claim can only be obtained when the state fails to fulfill important requirements of justice (Buchanan 1999: 54).

The NSD theory, on the other hand, does not require that a national group prove that it has a legitimate claim. Without requiring such a proof, the NSD theory would sanction a national group's secession even when the state performs the requisite functions satisfactorily. This clearly violates the just-cause theory of territorial claim, which holds that just states are entitled to territorial integrity.

Supporters of the NSD theory respond to this challenge differently. Nielsen suggests that Buchanan's theory assumes the principle of territorial integrity ueber alles, and that such a principle is to be rejected because it is based on a morally arbitrary, statist conception of territorial sovereignty (1996: 128). Moore argues that Buchanan's theory of territorial claim is not the most cogent theory precisely because it fails to include what she thinks a good theory of 
territorial claim should include, namely, a national group's claim to its own territorial area. In any case, Buchanan's objection to the NSD theory can only convince those who already subscribe to his just-cause theory. His theory of territorial claim is his theory of secession, i.e., the just cause theory. Saying that the NSD theory fails because it fails to meet the requirements set by the just-cause theory is no different from criticizing socialism for failing to meet the requirements of libertarianism — of course socialism fails when judged by libertarian criteria! Likewise, the NSD theory does not fulfill the requirements set by the just-cause theory. Nevertheless, this does not give us reason to reject it.

Although I agree with Buchanan that an adequate theory of secession must include an analysis of institutional morality as an integral part, I do not believe that his specific criteria help us determine whether a theory is compatible with the demands of institutional morality. To begin with, one may agree that the NSD theory fails to fulfill the requirements of minimal realism as well as incentive compatibility. But this does not seem to undermine the moral value of the NSD theory-many other morally defensible theories once failed to satisfy these two requirements. If we were to abandon these theories because they failed to fulfill these two requirements, we would not have made moral progress with our institutions. In other words, a theory can contribute to institutional improvement in spite of failing to meet these criteria. This clearly proves that these two requirements are not essential to institutional morality.

Here, Buchanan seems to confound two different types of values a political principle or theory can have-moral and practical. The former concerns a principle's moral permissibility, the latter its practical feasibility. Buchanan's criteria seem to be concerned with the latter, but not so much with the former. The requirements of minimal realism and incentive compatibility highlight the problems that would likely arise if the NSD theory were to be carried out in 
practice. That is, they reflect the theory's low practical value. However, as I mentioned earlier, many morally defensible principles once failed to satisfy these two requirements; nonetheless, we still made moral progress by formally including these principles in institutions. This shows us that a principle's low practical value does not undermine its moral value; even a principle with low practical value can have high moral value.

To be clear, I am not suggesting that minimal realism and incentive compatibility can be ignored. Rather, I am only clarifying their value - they have practical value, not moral value. Buchanan's criteria can help us determine the practical value of a theory; however, they cannot help us determine its moral value or whether it is compatible with morally defensible elements of existing institutions. To provide a convincing account of institutional morality, Buchanan's primary focus should be, as he suggests, on the moral principles and values that guide our institutions. That is, he should be concerned with those principles that have moral values. Yet, his criteria fail to include these values, for an account of a theory's practical values does not help us determine its moral value. Thus, even if we agree with Buchanan that institutional morality matters, we need not accept his criteria.

Accordingly, Buchanan's critiques of the NSD theory based on these specific criteria are not justified. Specifically, because these criteria do not reflect the requirements of institutional morality, they do not help us determine whether a theory is compatible with morally defensible elements of exiting institutions. In other words, failing to meet these criteria does not mean failing to meet the requirements of institutional morality.

\section{Lacking Holistic Institutional Morality}


Because Buchanan's criteria do not accurately reflect the content of institutional morality, they fail to show that the NSD theory would be incompatible with the demands of holistic institutional morality. Nevertheless, there is a concern that the NSD theory fails to include as an integral part an analysis of institutional morality. Notwithstanding Buchanan's failure to provide specific guidance on the demands of institutional morality, his methodological framework still seems generally sound - the right to secede is inherently institutional, and thus an adequate theory of secession must consider the right's overall impact on existing institutions. Buchanan may fail to articulate the specific demands of institutional morality; nonetheless, he seems right to demand that theories of secession engage in holistic institutional moral reasoning. If so, wouldn't the NSD theory still be considered defective?

This claim presents a serious problem for the NSD theory, which does not discuss its impact on or compatibility with existing political institutions. Although supporters of the theory clarify that their theories concern only the prima facie right of a national group to secede and thus allow institutional impacts to be weighed in actual decision-making, this information is not an integral part of their theory. That is, in deciding whether a group has the right to secede, the NSD theory does not take into consideration how this right affects existing institutions. According to Buchanan's methodology, the analysis of a right's overall impact must be an integral part of any adequate theory of secession. Without it, an argument for the right to secede would be incomplete, and could not justify a right to secede. How should the NSD theory respond to this challenge?

Although I disagree with Buchanan's specific criteria, I agree with his critique that the NSD theory is flawed due to its lack of an investigation of institutional morality. The right to secede is essentially institutional, and we cannot decide whether there is such a right until we 
determine its impact on relevant institutions. In this section, I will discuss how supporters of the NSD theory respond to this particular challenge. To defend their theory against Buchanan's objections, supporters of the NSD theory have come up with different responses. Here, I will discuss three. The first argues that Buchanan's claim, which holds that the right to secede is inherently institutional, is based on an implausible concept of right. The second argues that the NSD theory attempts to justify a purely moral, non-institutional right to secede; hence, Buchanan's criticism is irrelevant. The third acknowledges that, although the right to secede is institutional, Buchanan's methodology for institutional morality is wrong.

\subsection{A Problematic Concept of Right}

Moore believes that Buchanan's theory presumes an implausible conception of rights. Buchanan claims that the right to secede is inherently institutional; thus, to determine whether a national community has this right, one must first examine the impact of formally recognizing this right. Moore points out that this conception presupposes that the moral rights and duties we have flow from the institutional structure of our society (2001: 204).

However, Moore argues that this presumption is implausible. Were it true, then prudential considerations, such as whether a right's recognition would result in bad consequences, would have to be taken into account when we decide whether or not to recognize that right. This, in turn, implies that it could never be imprudent to exercise a right-if consequential considerations must be taken into account in determining whether there is a right, then imprudence would be inhibited in the process. It could then hardly be the case that a person can imprudently exercise a right, because relevant prudential considerations were supposed to be taken into account when deciding whether there is such a right. However, one may reasonably claim that a person has a right, but it would be imprudent or unwise for her to exercise this right. 
For instance, every U.S. citizen has the right to pursue a career as a U.S. Congressman. However, if a person lacks the requisite qualities, it would be quite imprudent for her to exercise this right. Therefore, there is something wrong with Buchanan's claim that the right to secede is inherently institutional; it rules out the logically possibility of an imprudent right.

There are, I think, two problems with Moore's argument. First, regardless of the conception of rights that is involved, prudential considerations for institutions are quite different from prudential considerations for individuals. The interests of a collective entity are not always reducible to the interests of individuals. It is good for the U.S. to have Congressional Representatives. However, it does not mean that it would also be good for each individual U.S. citizen to become a Congressman/woman. Those are two separate issues. When insisting on examining a right's impact on institutions, Buchanan's concern seems to be only with a right's impact on institutions and perhaps also society as a whole; his claim does not say anything about the impact on individual right-holders. Thus, it does not say whether it is prudent or not for the right-holder to exercise the right.

More importantly, Buchanan's claim that the right to secede is inherently institutional does not apply to all types of rights, but only to the right to secede, which he proves to be inherently institutional. Here, it would be useful to make a distinction between what are commonly called moral and legal (or institutional) rights. The former includes rights an agent has by virtue of his or her qualities or by some voluntary action. For instance, a person has human rights just by virtue of being a human being; rights and duties can also be created by an exchange of promises. On the other hand, legal or institutional rights are those granted by social or political institutions. One enjoys these rights only if they are formally recognized by public institutions. Not all moral rights are institutionally recognized, such as the right to have friends 
(Marmor 2007: 233-4). Similarly, not all legal rights are moral rights, e.g., the right to operate motor vehicles. So long as Buchanan's claim applies only to institutional rights but not moral rights, his claim would not have the implausible implications that Moore was concerned with.

\subsection{The Right to Secede-Moral vs. Institutional}

Both David Miller and Moore argue that although the NSD theory lacks an investigation of institutional morality, it can nevertheless be justified. They believe that their theory justifies a purely moral and non-institutional right to secede; thus, Buchanan's criticism, which applies only to institutional rights, does not apply to their theory.

In the end of the last section, I briefly mentioned two possible kinds of rights, i.e., moral and institutional. Here, to understand the response from NSD supporters, we must look at the corresponding distinction between two possible kinds of rights to secede. Here, I will utilize Buchanan's formulation from his earlier article. There, he distinguishes between two closely related but separate questions:

1. Under what conditions does a group have a moral right to secede, independently of any questions of institutional morality and in particular apart from any consideration of international legal institutions and their relationship to moral principles?

2. Under what conditions should a group be recognized as having a right to secede as a matter of international institutional morality, including a morally defensible system of international law? [italics added] (1997: 31-32)

The first question concerns the moral permissibility of a group's claim to secede, and the right 
that it focuses on is a moral one. On the other hand, the second question concerns the right's institutional adequacy, and the right in question is institutional. For the sake of brevity, I will call the first question the moral question and the second the institutional question.

According to Buchanan, the moral question can be answered in an "institutional vacuum (1997:32)." That is, it can be studied even if there is no corresponding institution. Moreover, even if corresponding institutions exist, the moral question can be studied without considering its impact on or compatibility with these institutions. In other words, this question is preinstitutional (Altman \& Wellman 2009: 54). Accordingly, a philosopher can study and answer the moral question without first considering the institutional question, which requires a study of relevant institutions.

On the other hand, because the right considered in the institutional question is meant to be formally included in political institutions, such as international law or domestic constitutions, philosophers working on this question must take into consideration its feasibility. In particular, because this right is expected to be incorporated by current legal and political institutions, a theory must take into account the right's impacts on and compatibility with these institutions. This is a task that can be ignored by those working on the moral question.

If the above distinction between moral and institutional rights to secede makes sense, then, a defender of the NSD theory could argue that her project is different from Buchanan'swhile Buchanan's theory aims to addresses the institutional question, the NSD theory attempts to answer the moral question. In other words, this theory is concerned only with justifying a moral right to secede. Because this right does not have any institutional implications, it can be worked out without considering its impact on existing institutions. This moral right can be entirely independent of these institutional issues. Therefore, Buchanan's objection is utterly irrelevant. 
This is how Miller defends the NSD theory. In responding to Buchanan's criticism, he insists that the NSD theory still provides a sound answer to the moral right question and should thus be taken into account when deciding whether a group should be recognized as having the right to secede (1996: 264). He believes that a purely institutional approach like Buchanan's cannot be satisfactory because it is likely to be biased in favor of some procedural criterion for deciding whether a group has the right to secede. However, such an approach necessarily ignores the substance of the identity of the seceding group, which Miller believes is absolutely relevant for determining relevant claims. Arguing that a nation has good reasons to become an independent state and that a state has good reasons to become a nation, he emphasizes that his argument does not argue explicitly in favor of an institutional right to secede, although it does justify a group's prima facie or presumptive right to self-government (1998: 261-282). At any rate, this right is not necessarily institutional, but is purely moral.

In responding to this suggestion, Buchanan argues that those working on the moral right question make a mistake regarding the priority of these questions (1999: 34). What matters most, according to Buchanan, is the institutional question. There are two reasons for its priority. First, there is practical urgency for solving the institutional question while the moral right question can wait. In his early article, Buchanan observes that secessionist movements "tend to have international consequences that call for international responses (1997: 32-33).” Accordingly, there is practical urgency for working out adequate institutional responses to these movements. Since a theory of secession is meant to be incorporated by relevant legal or political institutions, it should not merely be abstract philosophical theorizing. Instead, a desirable feature that such a theory ought to possess is that it can be feasibly implemented by relevant institutions or can provide useful guidance for institutional reform. If a theory were infeasible, or if the costs of its 
implementation were unreasonably high, then it could hardly provide helpful guidance for institutional reform. Regardless of the soundness of such a theory, it would be useless and thus unattractive (1997: 59-61). Second, as explained in 2.1, the right to secede is, as a conceptual matter, inherently institutional. Therefore, for both practical and conceptual reasons, Buchanan believes that we should prioritize the institutional aspect of the right to secede.

In addition to criticizing the NSD theory for wrongly prioritizing the moral question, Buchanan also suggests that if defenders insist that this theory is purely moral and has no institutional implications, then the NSD theory is even more irrelevant to our institutional design than it first appeared to be(2004: 347).

Notice that Buchanan never denies that it is possible to defend a non-institutional, moral right to secede. ${ }^{6} \mathrm{He}$ has never denied that supporters of the NSD theory may nevertheless successfully justify the moral right of a group to secede, although they are mistaken about the priority of the moral and institutional questions (1999: 31-34; 2004: 384). For Buchanan's criticism to apply, the question is not whether the NSD theory justifies a moral right to secede, but whether the right it claims to justify is institutional or not. Recall his argument for the thesis that the right to secede is inherently institutional. Any claim of a right to secede implies both that the group has the right to create its own state and that others have the duty not to interfere, where both the right and the duty involve an institutionally defined entity. If so, then a non-institutional right to secede, be it moral or not, would be utterly incomplete. Therefore, unless the right the NSD theory defends does not imply this right and duty as we normally assume it does, otherwise, Buchanan's requirement for institutional morality still applies.

To defend their approach, some supporters of the NSD theory bite the bullet and suggest

\footnotetext{
${ }^{6}$ Buchanan does claim that "both ideal and nonideal theory must be institutional because the right to secede is inherently institutional." However, this claim seems to be one about the methodology for determining whether there is a right to secede. It is not directly a claim about the right itself (2004:346).
} 
that the right their theory justifies does not have the institutional implications that Buchanan's claim involves. In this way, they avoid the problems Buchanan attributes to them. Unfortunately, the price of biting this bullet is rather considerable; it results in the marginalization of their theory with regard to institutional reform. As Buchanan suggests, if a theory does not have any institutional implications, then it is not clear how it can provide useful guidance for institutional reform. The theory then becomes irrelevant.

Thus, supporters of the NSD theory must explain why or how the theory is still pertinent — they must explain how a purely moral, non-institutional theory could nevertheless be relevant to institutional reform. To do so, some supporters suggest that their methodology is different from Buchanan's. What they try to do is defend a moral right first, and then consider how to institutionally implement this right. They believe that as long as they justify a moral right of a national group to secede, this automatically implies that institutions should be reformed so that this right receives adequate recognition. In the following section, I will consider whether this response successfully defends the NSD theory.

\subsection{Defending the Normative Superiority of Ideal Theory}

One way to defend the NSD theory is by defending its methodology, i.e., ideal theory. Some philosophers acknowledge that the right to secede is in some sense institutional; however, this does not entail that we must follow Buchanan's method of institutional morality. Buchanan's theory begins by examining existing institutions and then considering whether the inclusion of a new right or principle would be compatible with those institutions. It is commonly believed that his approach is that of nonideal theorizing. However, nonideal theorizing is problematic, because it tends to entrench the status quo. The NSD theory, on the other hand, begins by considering 
what would happen in ideal situations and is therefore a form of ideal theorizing. Ideal theory, supporters of the NSD theory claim, is free from those unjust elements of the status quo and thus normatively superior to nonideal theory. Consequently, it should guide institutional reform.

This is how some philosophers defend the NSD theory. They acknowledge that the right to secede is institutional, and that the NSD theory lacks an analysis of its overall impact on and compatibility with existing institutions. However, they see nothing wrong with their approach. Their theory is based on a different methodology. Consider, for instance, Moore's strategy:

While I think we shouldn't adopt an institutional theory of secession in Buchanan's sense, he is right to suggest that one goal—although not necessarily the pre-eminent goal—in reasoning normatively about secession is to consider how to institutionalize a right to secede in a state or in international organizations. Indeed, many of the theories that Buchanan criticizes attempt to do just that. Unlike Buchanan, however, they attempt to establish basic principles first, and then try to implement them in ways that will avoid the negative effects. They are not trying to develop "a morality that is free of all institutional constraints," in Buchanan's phrase. Rather, they are trying to develop principles that should be incorporated (ideally) in international legal regimes or in domestic constitutions and are sensitive to these constraints when they apply the principles [italics added] ( 2001: 205-206).

Nielsen, too, argues the NSD theory purports to be an ideal theory, for liberal democratic societies, which involves thinking institutionally about what international law concerning secession would look like under ideal conditions [italics added], i.e. under conditions in which states in such societies actually 
behaved in accordance with the moral principles embedded in the very idea of liberal democratic society, e.g. respected human rights, were committed to a principle of equal respect for all persons with its prohibitions on exploitation, manipulation, and the like and is, as well, a society committed to achieving and sustaining autonomy and indeed as much as possible equal autonomy (1998: 130).

Although supporters of the NSD theory acknowledge that nonideal theory is, as Buchanan suggests, more urgent because it tells us how we can move toward the ultimate goal of institutional reform, ideal theory is nevertheless normatively superior because it specifies that ultimate goal.

In addition to defending the superiority of ideal theory, Nielsen also suggests that nonideal theory is inadequate because it is likely to be biased in favor of the status quo (1998: 128). However, it is not clear why the status quo should be given such preferential status. This type of presumption would likely ignore existing injustices and allow them to be preserved by nonideal theorizing. The resultant theory would be conservative in an inadequate way —it would be likely to preserve many unjust or undesirable features, i.e., morally indefensible elements, of actual institutions. For instance, a much criticized point in Buchanan's argument is his emphasis that the NSD theory is not likely to be accepted by the lawmakers of real international law, i.e., actual states. True as that may be, it is not clear why this fact should be given so much weight in normative theorizing. It arbitrarily favors the interests of actual states while ignoring those of national communities. Buchanan's nonideal theory readily yields to the demands of actual power-holders (1997: 42). How could such a theory help us make any moral progress? Accordingly, beginning from nonideal theory is unjustifiable, because it necessarily gives a free 
pass to factual injustices. Therefore, philosophers should still consider these issues by engaging in ideal theorizing and letting the resulting theory guide our practice.

Consequently, the NSD theory, with its methodological foundation in ideal theory, is considered normatively superior, and should in some sense guide our institutional reform. Supporters of this theory believe that as long as they can prove that the moral right of a group to secede would be recognized in an ideal situation, they will have provided adequate justification for that right. In such a case, institutional provisions should be made so that this moral right receives suitable recognition. Moreover, if existing institutions are not compatible with such a right, these institutions should be reformed so that this moral right could be adequately recognized (Nielsen 1998:128). We should not abandon this right only because it would be incompatible with existing institutions.

Is ideal theory normatively superior? Does nonideal theory necessarily entrench the status quo? Does this mean that Buchanan's methodology is defective? Not necessarily. Whether this is so depends on what makes a theory ideal or nonideal. Although both Buchanan and the NSD theorists speak as if there were a commonly accepted notion of the distinction between ideal and nonideal theories, this is not the case, for there is evidence that they have very different understandings of the distinction between ideal and nonideal theory. Thus, both sides are talking past each other. Before I explain how this is so, let me first consider what I believe to be the fundamental problem with the methodology adopted by the NSD theory. Here, Buchanan explains very well what is wrong with the particular type of reasoning the NSD theory employs: [t]he simple but neglected point is that one cannot go from a moral argument for the soundness of a particular course of action in a single (usually highly idealized) type of case to a general principle that is suitable for institutionalization [italics added] (2004:23). 
Buchanan is right to suggest that one should avoid justifying a right or principle by considering one single, highly idealized situation. This type of reasoning inevitably ignores the problems that would likely arise if the right or principle were exercised in the real world along with other existing principles. The effect of including a new right is not always a matter of adding something new on top of a wholesome aggregate that is the status quo; it often causes expected or unexpected chemical changes.

Still, even if the NSD theory is defective in this respect, this does not mean that we must prefer Buchanan's theory. Although he points out a problem with the NSD theory, this does not explain why we should favor his theory. As Nielsen suggests, nonideal theorizing often ignores existing injustices and is thus deeply flawed. If so, we do not have good reason to prefer Buchanan's theory over the NSD theory. We are left with two theories, each with their own problems.

I believe that there is a way for Buchanan to avoid the problem his opponents raise for his view. Before I explain how it works, I must first clarify a misconception shared by both Buchanan and his opponents - the assumption that Buchanan's theory of institutional morality is nonideal theory and must favor the status quo.This is a wrong assumption; institutional morality need not entrench the status quo.

In the literature, it is commonly assumed both by Buchanan and his opponents that the NSD theory is ideal theory, and Buchanan's theory is nonideal theory. Given these claims, both Buchanan and NSD theorists also seem to agree that if one successfully defended the normative superiority of ideal theory, she would then effectively justify the NSD theory; similarly, if she successfully defended the superiority of nonideal theory, she would then effectively justify 
Buchanan's theory of institutional morality. Not surprisingly, both sides spend a considerable amount of time arguing for the superiority of ideal and nonideal theories, respectively.

Buchanan never denies the above claims. In fact, given his strong criticism of NSD's ideal theorizing, we can safely infer that he also believes that his own theory is nonideal (1997:60). In addition, a rather surprising fact is that he never even tries to dissociate his theory from the problems that his opponents are concerned with regarding nonideal theory—namely, existing injustices. His arguments are mainly focused on explaining why the NSD theory is useless, and how his theory directly addresses issues about institutions. Naturally, many philosophers are still worried about the entrenchment of the status quo and its association with actual injustices.

However, I think there are good reasons to question these claims - must the NSD theory be ideal theory? Must Buchanan's theory be nonideal theory? In particular, there is good reason to question whether Buchanan and the NSD theorists even share the same notion of what makes a theory ideal or nonideal. As I will show in the next paragraph, an examination of their debate reveals that the parties involved have very different notions of what makes a theory ideal or nonideal. Recently, John Simmons points out that there actually are several different types of distinctions between ideal and nonideal theory; there are also different types of nonideal theories (2010: 17). If so, then unless Buchanan and his opponents share the same notion of the ideal / nonideal distinction, an objection to ideal theory would not automatically imply that the NSD theory was wrong. Likewise, an objection to nonideal theory would not immediately mean that Buchanan was wrong. In other words, unless one rightly points out a problem for the kind of ideal theory that the NSD theory is based on, her critique of ideal theory will not explain why the NSD theory is wrong. Similarly, unless one attacks the kind of nonideal theory Buchanan's 
theory is based on, her objection to nonideal theory will not imply that we should reject Buchanan's theory.

Let us consider how Buchanan and his opponents understand the distinction between ideal and nonideal theory. First, consider Buchanan's objection to the NSD theory. He argues that because the NSD theory is based on the ideal theoretical assumption of perfect compliance, it can hardly provide useful guidance for actual institutional reform because our world is not like that (1999: 60). In responding to this challenge, Nielsen clarifies that although the NSD theory is ideal theory, it does not mean that it must also assume strict compliance (1998: 130-131). His methodology is ideal theory because it involves a counterfactual ideal conception of a liberal democracy, not because it must assume perfect compliance. As we can see, Buchanan might have correctly pointed out a problematic feature of a certain type of ideal theory; however, even if this objection successfully demonstrates the problem with that type of ideal theory, this does not mean that the NSD theory shares this feature or has the same problem. In other words, Buchanan's argument against ideal theory, even if successful, does not refute the NSD theory.

Let us also consider how Nielsen criticizes Buchanan's institutional morality theory. His main concern with nonideal theory is that it tends to entrench the status quo and allow unjust features of the real world to be preserved. However, if Buchanan's institutional morality can dispense with these elements - that is, if it can be free from those unjust, morally indefensible elements of institutions - then it need not have the same problems that certain nonideal theories have. The most important question is whether Buchanan's institutional morality can be free from these features that we do not like about nonideal theory, namely the entrenchment of the status quo. If it can, then there is no reason for Buchanan to defend nonideal theorizing or dwell on the complicated debate regarding the priority of ideal or nonideal theories. In other words, an 
argument against nonideal theory would not necessarily be an argument against Buchanan's theory—it would be so only if the theories share the feature that is under attack. However, if this is the case, then philosophers should directly discuss the problematic feature and explain why it undermines the theory's credibility; there is no need to take a detour and tackle the complicated debate between ideal and nonideal theories.

Here, we can see that in the examples I just mentioned, Buchanan may have pointed out a problem for some type of ideal theory, and Nielsen may have pointed out a problem for some type of nonideal theory. However, neither successfully points out a problem for the NSD theory or Buchanan's theory. Buchanan and Nielsen apparently have very different understandings of ideal and nonideal theories — one seems to think that the distinction is about the assumption of perfect compliance, the other about counterfactual conditions. The fact that they have different conceptions of ideal and nonideal theories is not surprising given the fact that philosophers today are still debating what makes a theory ideal or nonideal. In any case, to engage in a substantive debate concerning secession, philosophers should directly tackle the problems that Buchanan's institutional morality or the NSD theory has, not the problems that ideal or nonideal theory in general has. There is no need to take a detour and defend ideal or nonideal theorizing.

Regardless of the conceptual confusion involved in distinguishing between ideal and nonideal theory, the most important task for defending Buchanan's methodology is explaining how it can be free from the unjust elements in existing institutions. Here, it may be worthwhile to consider a more plausible understanding of institutional morality. This conception would explain why, even though we should be concerned with institutional morality, we need not favor the status quo or accept injustices in existing institutions. 
In 2.2, I constructed what I take to be the best interpretation of Buchanan's methodology of institutional morality. Very briefly, one begins by identifying the moral principles that guide existing institutions, then considering how the inclusion of a new right affects these institutions, and then considering in a holistic manner the overall impact of this right's implementation. Now, assuming that we have a rough estimate of a right's general impact on existing institutions, how do we decide which result to choose?

In principle, there are many ways in which one can make this decision. Here, I will discuss two possible guiding principles that could help us settle this matter. They are discussed because they concern an adequate understanding of institutional morality and its primary objective. The first holds that we should choose the right that would generate the result that best preserves the moral values embraced by existing institutions. The second holds that we should choose the right that would bring about the best overall result, which may or may not be the one that best preserves the moral values embodied by existing institutions. The first principle would not likely sanction drastic changes in existing institutions. However, with the second principle, drastic changes in existing institutions would be acceptable if they would, by and large, bring about a better (or even the best) overall outcome. While the first option prioritizes the status quo, the second does not.

Which principle should we choose? One common understanding of Buchanan's theory is to read it as choosing the first principle. There is indeed strong evidences indicating that this is Buchanan's real choice. For instance, he puts strong emphasis on a right's impact on existing institutions. In addition, his specific criteria for institutional morality—including progressive conservatism, minimal realism, and a cogent theory of territorial claim-show a strong tendency toward conservatism. Close reading of his work supports this conservative understanding of his 
methodology.

Nonetheless, given Buchanan's emphasis on holism with respect to institutional morality, I think he should choose the second principle. That is, we should go after the best overall outcome. There is no plausible reason to assume that he must prioritize or try to conserve the moral principles and values in existing institutions. There is also no good reason why he should not prohibit trade-offs between new and old principles if this would lead to a better overall outcome. Conservatism with regard to institutional reform is not necessary to make sense of the idea of holistic institutional morality. In other words, institutional morality need not entrench the status quo. So long as its focus is on the best overall outcome, it would not necessarily favor existing institutions.

Now, one might suspect that there is a more subtle way to be conservative about institutional reform without blatantly requiring that the process result in a minimalized impact on existing institutions. That is, one can assign greater weight to the moral principles and values of existing institutions. This would still prioritize the status quo, even though it does not appear that way.

Whether one should assign greater weight to moral principles and values of existing institutions depends on our judgment about their moral weights or importance. It might be the case that some of them are indeed more important, in which case we surely should assign them greater weight in our calculation. Some of these principles and values may not be that important, and there is no reason why we should grant them greater weight in our estimation. At any rate, there is no reason to assign a moral principle or value a greater weight just because it is a part of the status quo. Institutional morality need not entrench the status quo.

It is not clear which theory of secession this new concept of institutional morality would 
favor. Until we sort out the moral principles and values involved in current institutions, we cannot announce who the winner is in this competition for the best theory of secession.

\section{Conclusion}

In this paper, I have considered Buchanan's conception of institutional morality and the objections to the NSD theory that flow from this conception. While I agree with Buchanan that a good theory of secession must engage in what he calls institutional moral reasoning, I believe that his own conception of institutional morality is mistakenly narrow—in particular, he confuses the practical value of a theory with its moral value. The modest aim of this paper is only to point out this mistake. A comprehensive examination of institutional morality requires separate discussions. Before we work out the details of the demand of institutional morality, we cannot determine which theory is better, the NSD theory or Buchanan's just-cause theory.

Acknowledgement

The author would like to thank Professor Andrei Marmor and Professor Mark Schroeder for their comments on an earlier draft. She would also like to thank Miss Alida Liberman for proof-reading the paper.

\section{Bibliography}

Altman, A. \& Wellman, C. H. (2009). A Liberal Theory of International Justice. New York, NY: Oxford University Press.

Brilmayer, L. (1989). Consent, Contract, and Territory. Faculty Scholarship Series. Paper 2541. http://digitalcommons.law.yale.edu/fss_papers/2541. 
Buchanan, A. (1991). Secession: The Morality of Political Divorce from Fort Sumter to Lithuania and Quebec. Westview Press. (1997). Theories of Secession. Philosophy and Public Affairs, 26 (1), 31-61 (1999). Theorizing Nationalism (Normatively): The First Steps. In R. Beiner (ed.) Theorizing Nationalism (pp. 51-66). Albany, NY: State University of New York Press. (2004). Theories of Secession. Justice, Legitimacy, and Self-Determination: Moral Foundations for International Law. New York, NY: Oxford University Press.

Kymlicka, W. (1995). Multicultural Citizenship. New York, NY: Oxford University Press.

Margalit, A. \& Raz, J. (1990). National Self-Determination. Journal of Philosophy, 87(9), 439461.

Marmor, A. (2007). Law in the Age of Pluralism. New York, NY: Oxford University Press. Miller, D. (1995). On Nationality. Oxford: Clarendon Press. (1996). Secession and the Principle of Nationality. In J. Couture, K. Nielsen, \& M. Seymour (eds.) Rethinking Nationalism (pp.261-82). Canadian Journal of Philosophy Supplementary Volume 22. University of Calgary Press, Second Printing, 2000.

Moore, M. (2001). The Ethics of Nationalism. New York, NY: Oxford University Press. Nielsen, K. (1998). Liberal Nationalism and Secession. In M. Moore (ed.) National SelfDetermination and Secession (pp. 103-133). New York, NY: Oxford University Press.

Patten, A. (2002). Democratic Secession from a Multinational State. Ethics, 112(3), 558-586.

Wayne, N. (1998). The Ethics of Secession as the Regulation of Secessionist Politics. In M. Moore (ed.) National Self-Determination and Secession (pp.34-61 ). New York, NY: Oxford University Press.

Simmons, A. J. (2010). "Ideal and Nonideal Theory," Philosophy and Public Affairs, 38(1), 5-36. 
Tamir, Y. (1993). Liberal Nationalism. Princeton, NJ: Princeton University Press. 